\title{
Contramão, de Henrique Schneider: a escrita à deriva
}

\section{Contramão by Henrique Schneider: the drifting writing}

Francisco Renato de Souza

Universidade Federal do Rio de Janeiro, Rio de Janeiro, Rio de Janeiro / Brasil paconato_@hotmail.com

Resumo: Este artigo investiga o movimento não objetivo da escrita literária na narrativa Contramão, de Henrique Schneider, a partir da perspectiva do escritor francês Maurice Blanchot sobre a literatura, assim como analisa o paralelo, também proposto por Blanchot, entre a linguagem corrente e a linguagem característica do texto ficcional, pautada pelo imaginário e, portanto, contrária às regras vigentes no mundo da realidade. Como resultado dessa investigação, percebe-se o desvio do personagem da ordem para a errância como o movimento característico da escrita literária, que se desenvolve sem objetivação e por uma pluralidade de possibilidades, uma vez que não intenta um propósito único. Conclui-se então, que a dimensão propícia para o desenvolvimento dessa escrita se dá no terreno do imaginário, uma vez que a irrealidade estende o movimento da errância ao infinito, proporcionando à linguagem ficcional o movimento incessante e interminável, incompatível com a finitude do espaço do mundo corrente.

Palavras-chave: Contramão; Henrique Schneider; Maurice Blanchot; escrita; errância; deriva.

Abstract: This article investigates the non-objectiveness of literary writing in Contramão, by Henrique Schneider, from the perspective of the French writer Maurice Blanchot. It also investigates the parallel, proposed by Blanchot, between the language of current world and the characteristic features of fictional texts, guided by the imaginary and 
therefore opposed to the existing rules of the current world reality. Because of this investigation, we realize that there is a character's drift from the order to wonderings, as a characteristic of literary writing movement, which develops without objectification and from a plurality of possibilities, since it does not attempt to a single purpose. It follows, then, that a favorable dimension to the development of literary writing takes place in the imaginary field, since the unreality extends this wandering movement to infinity, providing this fictional language an incessant and endless movement opposed to the finitude of current world.

Keywords: Contramão; Henrique Schneider; Maurice Blanchot; writing; order; wandering.

Recebido em: 29 de abril de 2016. Aprovado em: 17 de abril de 2017.

A estrada é para fora, muito, e quando se foge com os automóveis o cerco da cidade não tem regresso nem repouso.

(Ramos. Circuito Fechado.)

A errância, o fato de estarmos a caminho sem poder jamais nos deter, transformam o finito em infinito.

(Blanchot. O livro por vir.)

A narrativa de Contramão, de Henrique Schneider, se inicia com o despertar de Otávio Augusto, personagem central do enredo, cena na qual o narrador descreve os movimentos matinais corriqueiros de um típico executivo de uma grande cidade, caracterizando também um homem metódico, ambicioso e indiferente a qualquer elemento que esteja fora do projetado quadro de sucesso empresarial e financeiro que o ainda jovem personagem traçara para a sua vida. Seguindo o projeto de vida que a mente calculista e metódica de Otávio Augusto elucubra, a narrativa se direciona para um desenvolvimento programado, linear e 
objetivado, por meio dos movimentos do personagem que só intenta o sucesso, se valendo de sua determinação e autoconfiança para alcançar a ascensão na metalúrgica do tio, empresa na qual ocupa o cargo de gerente de negócios - ocupação que assumiu tão logo se graduou em Administração de Empresas, como exige a persistência de um homem de 25 anos e profissão definida, com a vida inteira pela frente e todas as chances do mundo para ganhar dinheiro:

Minutos depois, limpo e novo, arejado e seco, trazia
ao corpo a roupa escolhida na noite anterior, cuidada e
impecável, retocando-se ao espelho com a mesma decisão
de todos os dias e acreditando que, aos vinte e cinco anos, o
sujeito tem toda a vida e muitas possibilidades pela frente
(SCHNEIDER, 2007, p. 8).

Esse mundo de múltiplas possibilidades disponíveis a quem pretende crescer, Otávio Augusto vislumbra de cima, da sacada do seu apartamento no décimo andar, de onde vê o despertar da cidade de Porto Alegre. Entretanto, como a sua atenção não poderia cair em digressão, se perdendo em qualquer beleza dessa cidade, ante a visão do Guaíba, da Redenção, do Gasômetro ou da Praça da Alfândega, o personagem vislumbra a cidade como o espaço propício para a aquisição de seu futuro material: "Otávio olhava para baixo e enxergava com outro olhar a Porto Alegre ali estendida: era a quase metrópole, junção considerável de prédios e cimento, dinheiro e negócios escorrendo nas salas certas, números e tabelas, percentuais e códigos" (SCHNEIDER, 2007, p. 10).

Um terceiro personagem ainda despertaria nesse primeiro capítulo, intitulado "Porto Alegre, de manhã": o carro de Otávio Augusto, a montaria privilegiada de um grande homem, a maravilha mecânica e importada que o executivo domava como a um animal indômito, recebendo com um prazer instantâneo o rosnado dócil do motor que, ao giro da ignição, acordava com o som uniforme de bicho saudável. Senhores de todos os espaços, homem e máquina se integram. Otávio Augusto se afivela no carro e no planejamento de mais um dia de negócios, revisando os compromissos e se felicitando pela perfeita programação. Quando, então, subitamente, um imprevisto corta a rotina do personagem e tira do rumo o direcionamento previamente calculado para a narrativa.

Como marca o substantivo no título do segundo capítulo, "Um instante em Porto Alegre", em um momento muito breve, um instante 
apenas, todas as diretrizes que até então guiavam Otávio Augusto são postas em xeque. Visando unicamente o seu futuro, já que se guia pelo lema: "O estudo sempre bem cuidado sobre o rumo a ser seguido, porque é impossível voltar atrás" (SCHNEIDER, 2007, p. 29), e concentrandose mais na revisão dos compromissos a cumprir do que no caminho que o levaria a eles, visto que se mantém permanentemente alheio ao mundo ao seu redor, pisa fundo no acelerador para ganhar um minuto (tempo é dinheiro!), no instante em que o semáforo amarelo se avizinha do vermelho. Quando, então, a brusca freada do carro ao lado lhe desvela a presença de uma menina e de um garoto, sua tentativa de freada não livrará seus corpos do baque contra a lataria do automóvel, sendo, um após o outro, arremessados ao ar com livros e cadernos, em meio ao barulho de sons de gritos e estalos de ossos se misturando com o sangue no para-brisa. Duas crianças de 13 ou 14 anos com o caminho interrompido; e os olhos de morte da menina grudados nos olhos de Otávio Augusto, que, naquele instante impossível de prever, perdido em incertezas, tem o seu lema revertido a "e tudo que queria era voltar atrás" (SCHNEIDER, 2007, p. 15).

A partir da cena do atropelamento, uma reviravolta se faz nos atos do personagem que, sempre guiado pela razão e pelo cálculo, seguira até então um movimento linear pautado pela ordem, resultando em uma vida segura, marcada pela previsibilidade e pela estabilidade. Otávio Augusto, então, talvez pela primeira vez, olha para trás. E ao ver os corpos inertes no asfalto o executivo pensa ter matado as crianças e destruído a sua própria vida. Perante tal incidente, que destoa absurdamente de tudo que fora tão meticulosamente previsto para a pauta do dia (desde já destruindo-a), a sua autoconfiança se dissipa e cede lugar ao medo: "Otávio sentiu o medo que lhe brotava invencível das entranhas, que nos outros chamaria de covardia, e este lhe ordenou, sem qualquer voz de razão e muito de desespero, que não ficasse ali para enfrentar aquela situação invencível" (SCHNEIDER, 2007, p. 18).

Esvaziada da capacidade do raciocínio, a mente de Otávio Augusto é povoada pelo medo, com imagens de linchamento, polícia, prisão, algemas e delegacias, impulsionando-o a uma fuga sem direção pelas ruas da cidade, desatino que se alimenta ainda pela aflição de, enfim, constatar que toda a sua agenda diária estava perdida. Desprovido de qualquer estratégia para lidar com a inesperada situação, decide pegar a estrada, afastando-se do seu espaço da ordem, Porto Alegre. Porém, seguindo uma necessidade natural de se ater a uma programação, demarca um ponto de 
chegada - ridiculamente escolhido apenas por uma descrente superstição, sem nenhum cálculo ou raciocínio lógico - para uma trajetória que, a sua revelia, já se desviava e o arrastava consigo para uma viagem sem objetivação, que seguiria pela via contrária, em contramão:

Fora do carro, a estrada corria apressada e as cercanias de Eldorado do Sul já se avizinhavam. Passou por um posto de gasolina e decidiu que iria mais longe: sem qualquer cálculo, sem saber verdadeiramente aonde chegaria, disse para si mesmo que a parada seria no sétimo posto. Sete sempre fora número de sorte para Otávio Augusto, embora custasse a admitir o que chamava de bobagens. Assim, ainda faltavam seis. Mais seis postos e pararia, distante daqui, tomaria um café e bem decidiria o que fazer (SCHNEIDER, 2007, p. 24).

A escolha do personagem direciona a narrativa que inicialmente acompanharia o cotidiano urbano de um executivo, através da rotina de um dia de trabalho marcada pela organização de uma previsibilidade calculada, para a viagem que se tornará uma sequência ininterrupta de desvios, derivados das inúmeras fugas que Otávio Augusto realizará a partir da sucessão de imprevistos que cortam o seu caminho. Cada ação que ele meticulosamente intenta elaborar pelo cálculo resulta em uma consequência desastrosa que o faz ir cada vez mais adiante e sem direção, porquanto se mantém fiel ao lema que tem como única diretriz o movimento contínuo de seguir em frente e nunca voltar atrás, arrastando, ou melhor dizendo, sendo arrastado pela narrativa para longe do espaço demarcado da cidade: "E não havia retorno possível, só lhe restava seguir em frente. Não podia voltar atrás" (SCHNEIDER, 2007, p. 32).

No entanto, ao cálculo meticulosamente preparado pelo personagem em toda a sequência narrativa do primeiro capítulo, "Porto Alegre, de manhã", se contrapõe a fala do narrador. Enquanto Otávio Augusto direciona o seu movimento para um futuro, mesmo que pretensamente previsível, o narrador acompanha esse movimento com a onisciência da impossibilidade de sua realização, finalizando o capítulo com a sentença que reverteria o intuito do personagem: "Tudo programado, felicitou-se, tudo afivelado no planejamento. / Só que o bom planejamento de Otávio Augusto não guardava espaço para o imprevisto" (SCHNEIDER, 2007, p. 12, grifo nosso). Na sequência, 
inicia a narração do capítulo "Um instante em Porto Alegre" com a descrição do momento fatal que varre toda a aspiração de futuro de Otávio Augusto para o vácuo da irrealização. Aspiração prematuramente descartada, visto que para o narrador ela já seria o saldo negativo de uma ação consumada: "Foi assim" (SCHNEIDER, 2007, p. 13). Em seguida, deixa o personagem à deriva, ao principiar o capítulo que doravante o colocará a mercê do movimento narrativo, "Pela estrada, no Rio Grande", com o questionamento que desafia a mente pautada pela previsibilidade do personagem: "E agora?" (SCHNEIDER, 2007, p. 17).

Esse questionamento se repetirá, pois, afastado da sua situação de segurança e ordem, o personagem é jogado à deriva, agindo irracionalmente a cada novo imprevisto que o movimento narrativo lhe impõe: "A mesma pergunta, repetida: e agora?" (SCHNEIDER, 2007, p. 35). Pois se Otávio Augusto ainda intenta delimitar uma trajetória na sua viagem de fuga, demarcando pontos de chegada, essas balizas são sucessivamente removidas pela sequência de imprevistos que o desvia do ponto previamente almejado, distanciando-o continuamente de seu ponto de origem e impelindo-o cada vez mais para um ponto que está sempre além do pretendido. A viagem de Otávio Augusto é, assim, um jogo de forças entre a tentativa de objetivação do personagem e a corrente sem direção na qual ele é jogado pelo movimento narrativo:

Montevidéu estava a seiscentos quilômetros, reto à frente, e Jaguarão a cento e sessenta, na mesma direção. O Chuí ficava a duzentos e sessenta quilômetros de onde estava, pegando a esquerda no próximo entroncamento. À esquerda, pelo caminho seguro - decidiu. / Soubesse que Jaguarão também ficava na fronteira, talvez sua vida adiante fosse diferente (SCHNEIDER, 2007, p. 106, grifo nosso).

$\mathrm{Na}$ tormenta psicológica pela qual atravessava e na qual temia se perder, "Agora era seguir adiante, as mãos tremendo mais do que antes e começando a implantar-se algo que beirava o desvario" (SCHNEIDER, 2007, p. 35), Otávio Augusto se atém aos pontos demarcados como fizera Ulisses, o herói grego da Odisseia, ao se atar ao mastro do seu navio, tapando os ouvidos com cera para evitar se deixar tragar pelo canto irresistível, e mortal, das sereias. Ao estabelecer uma relação entre a tentativa de planejamento e direção do personagem de Contramão com a técnica utilizada por Ulisses no seu encontro com as sereias, e assim traçar 
um paralelo entre a viagem de fuga de Otávio Augusto e a navegação dos marinheiros gregos, me remeto ao texto de Maurice Blanchot, "O encontro do imaginário", de o Livro por vir, no qual o escritor francês entrevê a impossibilidade de objetivação da escrita, ilustrada por ele pela aproximação do movimento do escritor na elaboração de sua obra com o movimento da navegação dos antigos marinheiros gregos, mais precisamente na sua relação com as mitológicas sereias.

As sereias, seres metade animal, metade mulher, enfeitiçavam os marinheiros com seus cantos e os atraíam para os rochedos, provocando sua morte, para devorá-los em seguida. Blanchot enfatiza a imperfeição desse canto, que não satisfazia completamente os navegantes, apenas dava-lhes a entender onde o canto realmente tinha começo, conduzindo-os nessa direção, não passando, assim, de um canto ainda por vir. Portanto, o canto era a navegação, a distância, e a revelação da possibilidade de percorrê-la, de fazer do canto o movimento em direção ao canto: "Entretanto, por seus cantos imperfeitos, que não passavam de um canto ainda por vir, conduziam o navegante em direção àquele espaço onde o cantar começava de fato. [...] O que era esse lugar? Era aquele onde só se podia desaparecer" (BLANCHOT, 2005, p. 03).

Todavia, apesar do caminho dado pelo canto, os navegantes ou se precipitavam em um ponto aquém deste ou o ultrapassavam, pois desejavam traçar racionalmente o percurso, não se deixando cair no abismo do canto. O fracasso dos navegantes se dava pelo planejamento da navegação, pela sua intenção deliberada de atingir um ponto certo. Para chegar ao local desconhecido do canto era preciso se deixar levar por ele, entregar-se a ele sem precauções ou planejamentos. Deixar-se levar pelo canto e a ele se entregar sem restrições é o movimento visto por Blanchot para a composição literária. E chegar ao ponto do canto e nele se deixar perder é escutar o chamado inumano dele, momento em que a narrativa, nas palavras do filósofo, "[...] torna-se a riqueza e a amplitude de uma exploração, que ora abarca a imensidão navegante, ora se limita a um quadradinho de espaço no tombadilho, ora desce às profundezas do navio onde nunca se soube o que é a esperança do mar" (BLANCHOT, 2005, p. 6).

Dessa forma, escutar o canto do inumano é também se deixar tragar por esse canto, um movimento que não pode se efetivar sem a entrega e perdição imprescindíveis de quem o experimenta. Blanchot ilustra o seu pensamento com duas passagens literárias: a do canto XII da Odisseia, de Homero, no qual o herói grego Ulisses burla o feitiço das sereias, amarrando- 
se ao mastro de seu navio e assim evitando ser tragado pelo canto sedutor do qual desfrutava. A essa entrega comedida, Blanchot contrapõe a do capitão Achab, que leva a sua busca incessante por Moby Dick, a baleia-branca que dá título ao livro de Herman Melville, aos confins do oceano em que se perdem caça e caçador: "Isso quer dizer que um se recusou à metamorfose na qual o outro penetrou e desapareceu" (BLANCHOT, 2005, p. 11).

A narrativa literária está ligada a essa metamorfose, transformando profundamente aquele que escreve na mesma medida que transforma a própria narrativa. A navegação prudente de Ulisses em direção ao canto, para Blanchot, ainda faz parte da navegação do mundo, no tempo do cotidiano dos homens, que alude a um objetivo e a um destino, e somente passa para o outro tempo, para aquela outra navegação, que é a passagem do canto real ao canto imaginário, através do movimento que é próprio da ação da metamorfose: "É ouvindo o canto das sereias que Ulisses se torna Homero, mas é somente na narrativa de Homero que se realiza o encontro real em que Ulisses se torna aquele que entra em relação com a força dos elementos e a voz do abismo" (BLANCHOT, 2005, p. 9).

Em Contramão, a metamorfose do seu personagem se dá no decorrer da trajetória de fuga que ele estabelece, primeiramente, para fugir das responsabilidades do atropelamento das duas crianças, mas que, no entanto, se multiplica em ações de delito que desconstroem os traços originais que demarcavam a figura de Otávio Augusto:

atropelamento (homicídio culposo, e de novo os olhos de morte da menina), omissão de socorro, fuga de batida policial, roubo de carro (e este carro, sem passar dos oitenta), lesão corporal (talvez seguida de morte) e furto de placas -, em quatro horas construíra o prontuário de um veterano (SCHNEIDER, 2007, p. 104).

Porém, o movimento inicial dessa fuga, que o distancia da navegação do tempo cotidiano dos homens, se dá no exato momento em que Otávio Augusto se vira para ver o resultado da batida do seu carro nas duas crianças.

O seu movimento em via contrária se dá, portanto, antes de ele iniciar a sua fuga, visto que ele se inicia no momento em que o personagem subverte a sua diretriz: "E sempre com o olhar para a frente: não se pode nunca voltar atrás". Da imagem dos corpos estendidos no chão, o personagem cria a cena do homicídio culposo, tecendo, a partir de então, toda a trajetória que se desenvolve paralelamente à realidade, 
e que o leva em direção ao mundo do imaginário, espaço no qual ele se desconstrói como ser do mundo e da ordem, e se reinventa pelo viés da imaginação: "À história que inventasse daria as respostas que quisesse; a história verdadeira não the concedia esta liberdade" (SCHNEIDER, 2007, p. 124). Desse modo, o enredo de Contramão se desenvolve por duas vias paralelas, a da navegação do mundo real, na qual as ações se dão como fatos, e que permanecem à margem da narrativa; e a navegação às avessas, aquela do imaginário, que é tecida pelas suposições, sempre equivocadas, de Otávio Augusto.

Esses dois mundos paralelos, que se desenvolvem simultaneamente e se opõem como duas faces do mesmo espelho, demarcam os dois estados do personagem de Contramão: Otávio Augusto, o executivo bem-sucedido de Porto Alegre, e o foragido sem identidade e sem rumo que se perde em uma trajetória na qual quanto mais avança, mais se distancia do seu estado original:

A imagem impiedosa que o retrovisor devolvia era a de um rosto descomposto, tocos e cascas de madeira compondo um ninho na pasta dos cabelos, a roupa empoeirada e o colarinho em puro desmazelo. $\mathrm{O}$ espelho era trincado e separava em dois o rosto de Otávio Augusto, atravessando-o como a divisa entre dois Estados e piorando ainda mais o que se podia enxergar (SCHNEIDER, 2007, p. 90).

Essa ambivalência do personagem, que o divide entre dois estados, o Rio Grande do Sul e o do povoado de Punta del Diabo, no Uruguai, se reflete nos capítulos "O outro dia, no Rio Grande" e "O outro dia, em Punta del Diablo". No dia seguinte ao do atropelamento, simultaneamente à chegada do personagem ao ponto "final" de sua trajetória, o narrador perscruta o que acontece no estado que Otávio Augusto deixara para trás, não apenas fisicamente como racionalmente, o estado da realidade, uma vez que, pelo prontuário narrado, nenhum dos quatro homicídios que o personagem pensou ter deixado no seu rastro se concretizara. Nenhuma morte resultou do atropelamento das crianças, nem do sequestro com agressão do velho Idalino, e tampouco do estrangulamento de Valdete, a amante ocasional de uma noite no Chuí. Da mesma forma, o personagem escapara ileso das pequenas contravenções, como o roubo de placas e a fuga da batida policial. Portanto, todo o movimento de Otávio Augusto, desdobrado de fuga em fuga, desabrochara das suposições da sua imaginação. 
Ao fugir seguidamente das mortes que julgara cometer, Otávio Augusto foi o único a morrer, como ser do mundo e da ordem, pois a sua trajetória de fuga o levou, paulatinamente, à sua própria descaracterização, comprovada pela decomposição da sua imagem refletida, que demonstra o apagamento das demarcações que traçavam o contorno inicial do personagem identificável. Dentre elas, o designador do referente fixo e único que é o nome próprio, que nessa obra é um fator importante no processo de caracterização do personagem:

Olhou-se no espelho e gostou do resultado. Da mesma forma que seu nome completo - Otávio Augusto Ribeiro de Souza - possuía todas as letras muito bem organizadas e sem qualquer possibilidade de se espalharem além do seu estrito lugar, ele não se permitia andar desarrumado (SCHNEIDER, 2007, p. 8).

Para Blanchot, no texto "A literatura e o direito à morte", do livro $A$ parte do fogo, a questão da nomeação está diretamente ligada à presença da morte. Se ao nomear algo eu aniquilo esse algo, tiro sua realidade de carne e osso, é porque a palavra me dá o que ela significa, mas antes o suprime. Assim, a palavra me dá o ser que, no entanto, me chegará privado de ser. $\mathrm{O}$ teórico reflete sobre a presença da morte na linguagem no ato da nomeação, já que através dela a pessoa (ou a coisa) nomeada passa a ser separada dela mesma, tendo a sua existência e a sua presença subtraídas e mergulhadas em um nada de existência e de presença, trazido pela linguagem. Segundo Blanchot, isso só se dá porque o ser nomeado é passível de morte, está ligado a ela e ameaçado por ela a cada momento de sua vida.

Dessa forma, a morte fala na fala de quem fala. Entre falante e ouvinte há a presença da morte, ela é a distância que os separa, mas também o que os impede de estar separados, haja vista estar nela a condição de todo entendimento. Se só a morte me permite agarrar o que quero alcançar, nas palavras ela é a única possibilidade de seus sentidos, afirma o teórico, já que o poder de falar em mim está ligado também à minha ausência de ser:

Eu me nomeio, é como se eu pronunciasse meu canto fúnebre; eu me separo de mim mesmo, não sou mais a minha presença nem minha realidade, mas uma presença objetiva, impessoal, a do meu nome, que me ultrapassa e cuja imobilidade petrificada faz para mim exatamente o efeito de uma lápide, pesando sobre o vazio (BLANCHOT, 1997, p. 312). 
Se, no mundo corrente, a linguagem mata pela possibilidade da morte, na linguagem literária a perspectiva muda, a literatura é a própria impossibilidade da morte, é a busca pelo momento precedente à morte dada pela palavra, pelo que estava ali antes da nomeação. E se a morte confere sentido à existência é porque possibilita o fim, aspecto natural da condição humana. Dar à literatura a impossibilidade da morte é darlhe o caráter do inumano, é desvincular a realidade do texto literário da realidade do mundo corrente. Estabelecer um fim é estabelecer um objetivo, é intentar um poder. E para Blanchot, a escrita literária é o oposto disso, é algo fora do poder, do objetivo certo, sendo a literatura o campo das possibilidades infinitas:

Quando recusa nomear, quando do nome faz uma coisa obscura, insignificante, testemunha de uma obscuridade primordial, o que, aqui, desapareceu - o sentido do nome - está realmente destruído, mas em seu lugar surgiu a significação geral, o sentido da insignificância incrustado na palavra como expressão da obscuridade da existência, de modo que, se o sentido preciso dos termos se apagou, agora se afirma a própria possibilidade de significar, o poder vazio de dar um sentido, estranha luz impessoal (BLANCHOT, 1997, p. 316).

Portanto, destituído de sua condição anterior, o personagem de Contramão se despe também de sua identidade, pois na sua feérica interpretação dos fatos, Otávio Augusto, o homem outrora respeitado e bem-conceituado (e renomado), se torna um fugitivo, provavelmente procurado pela polícia, que melhor se sairia quanto menos se deixasse notar; um anônimo perdido em uma viagem sem rumo, que no decorrer dessa trajetória se distancia do seu "Eu" anterior e se transforma em um outro: "É que, de alguma forma e sem que se desse conta, havia ultrapassado aquela borda, a linha estreita e perigosa que separa a razão do destemor impensado" (SCHNEIDER, 2007, p. 67). Afastado da razão e entregue ao destemor, Otávio Augusto se reinventa temporariamente como Jeison Pontes, a identidade que o personagem cria para se apresentar para Valdete, a amante ocasional que ele conhece na viagem de ônibus para o Uruguai. Jeison se apresenta como um escritor em viagem de pesquisa para a escrita de seu livro, pondo, assim, na dimensão do imaginário, da dissimulação e do engodo a sua própria trajetória, que 
se refletiria no movimento das linhas que se fariam obra: “- E sobre o que é que vai ser o livro? / - Ainda não resolvi muito bem, mas é a história de um cara que está viajando e se mete num monte de confusão" (SCHNEIDER, 2007, p. 125).

A viagem de fuga de Otávio Augusto, que o leva de Porto Alegre até Punta del Diablo, se desdobra, então, como a travessia do mundo da ordem para o espaço do imaginário, dimensão que não impõe limitações porque se estende infinitamente, através das múltiplas possibilidades de significações. Pelo logro, pela invenção, pelo disfarce, Otávio Augusto traça um novo contorno para si, se reinventando como um personagem antípoda àquele que mantinha um firme compromisso com a realidade:

Otávio tinha dois pés duros para a dança, mas nada impedia que Jeison, descompromissado da realidade, fosse exímio pé-de-valsa, bailarino de ganhar prêmios. E, se podia escrever, também podia dançar - era boa esta brincadeira de inventar a vida de alguém, enchê-la de qualidades e defeitos que melhor lhe aprouvessem (SCHNEIDER, 2007, p. 144).

Assim como Ulisses insiste em desfrutar do gozo do canto das sereias sem nele se perder, Otávio Augusto se prende ao mastro do cálculo e da objetivação. Ao atravessar a fronteira do Brasil com o Uruguai, acredita ter deixado para trás o espaço da desordem que o separava da sua condição primeira, e sentindo-se seguro das ameaças que a sua imaginação fomentara, intenta um novo plano, o de retomar a sua posição de moderno e promissor gerente de metalúrgica: "E pela primeira vez em toda a viagem não precisava atrapalhar o raciocínio com a necessidade da fuga, de lugar seguro, não precisava correr e salvar-se: já estava a salvo, e podia pensar apenas em como voltar melhor" (SCHNEIDER, 2007, p. 173). Entretanto, não há fim para o caminho daquele que se extravia pela errância, pois, como destaca Blanchot, em "O infinito literário: o Aleph", de O livro por vir, a errância é justamente a condição de se estar a caminho sem jamais poder se deter, sendo, então, o movimento que transforma o finito em infinito: "O lugar do extravio ignora a linha reta; nele, não se vai de um ponto a outro; não se sai daqui para chegar ali; nenhum ponto de partida e nenhum começo para a marcha" (BLANCHOT, 2005, p. 137).

A trajetória de extravio de Otávio Augusto diz assim da própria trajetória da narrativa de Contramão, pois essa se faz pelo desvio do espaço da ordem para o espaço da pluralidade do ilusório, do mundo da realidade 
para o da irrealidade, movimento errante que é o próprio movimento da escrita literária. Ao se extraviar da realidade dos fatos e seguir, tomando-a como realidade, a irrealidade de suas suposições, o personagem traça a trajetória que será narrada, aquela que se faz obra, e que deixa de fora de suas linhas o verdadeiro modo como as coisas aconteceram, verdade essa que pouco importa para a narrativa, pois para o seu personagem a única realidade que interessa é a contida na sua irrealidade:

A literatura não é uma simples trapaça, é o perigoso poder de ir em direção àquilo que é, pela infinita multiplicidade do imaginário. A diferença entre o real e o irreal, o inestimável privilégio do real, é que há menos realidade na realidade, pois ela é apenas a irrealidade negada, afastada pelo enérgico trabalho da negação, e pela negação que é também o trabalho. É esse menos, essa espécie de emagrecimento, de afinamento do espaço, que nos permite ir de um ponto a outro, à maneira feliz da linha reta (BLANCHOT, 2005, p. 140).

Assim, o movimento desordenado do personagem, desenvolvido em forma de fuga que não se pode percorrer em linha reta, se desdobra em espiral, pelo movimento errante que conduz à obra. De erro em erro, Otávio Augusto traça imaginariamente a cadeia de ameaças que o impele para o ponto que ele acredita ser o final: "A marca agora era outra; era preciso ir mais longe [...] O destino não era mais o sétimo posto de gasolina. / Era preciso atravessar a fronteira. / O destino era o Uruguai" (SCHNEIDER, 2007, p. 68). Entretanto, indiferente à objetivação e ao propósito que Otávio Augusto insiste em manter para o seu movimento, as linhas da narrativa de Contramão já o arrastaram por esse movimento incessante, que o fez estender, ponto após ponto, as demarcações previamente traçadas para a sua trajetória. O destino final, a cabana isolada no povoado de Punta del Diablo, abrigo no qual o personagem intenta rever racionalmente a sua trajetória errante e desordenada, para então retomar o domínio da sua vida, no propósito de voltar a ser Otávio Augusto Ribeiro de Souza, é um ponto inacessível, uma vez que no espaço literário o fim é o recomeço, pois esse espaço é o espaço do devir, e essa errância é infinita:

Antes de ter começado, tudo já recomeça; antes de ter realizado, repetimos, e essa espécie de absurdo que consiste em voltar sempre sem nunca ter partido, ou em 
começar para recomeçar, é o segredo da "má" eternidade, correspondente à "má" infinidade, que encerram, talvez, o sentido do devir (BLANCHOT, 2005, p. 137).

Desse modo, a trajetória pretensamente objetivada de Otávio Augusto mais uma vez, e pela última vez, é cortada pelo inesperado. Porém, o movimento em contramão que se repete inverte as posições de sujeito e objeto da cena: "Naquele segundo luminoso em que descobrira o que fazer e onde ficar, Otávio Augusto começou a atravessar a rua. / Sem olhar se vinha algum carro" (SCHNEIDER, 2007, p. 174). E o "Foi assim" (SCHNEIDER, 2007, p. 175) que inicia o último capítulo, "Um instante em Punta del Diablo", descreve mais uma vez o momento em que o imprevisto corta o caminho de objetivação de Otávio Augusto, dessa vez colocando-o como a vítima do atropelamento, arremessado ao ar com os mesmos sons de ossos estalados contra a lataria do carro e as marcas de sangue a manchar o para-brisa.

Um corpo inerte com olhos de morte (talvez...) fixos no olhar atônito do assustado motorista que retoma o movimento de fuga, fomentado pelo medo que poderá pôr em movimento uma nova trajetória errante, desviada da rota da realidade pela feérica concepção dos fatos, extraviando da vida e do mundo da ordem um novo personagem que se desconstruirá na trajetória que se fará obra, pois que seguirá o curso irracional do imaginário, arrastando-o para a irrealidade pelo movimento errante da escrita, que é incessante e interminável.

\section{Agradecimentos}

Ao Davi, pela insistência.

À Renata e ao Raphael (in memoriam), pelo elo.

\section{Referências}

BLANCHOT, M. A parte do fogo. Tradução de Ana Maria Scherer. Rio de Janeiro: Rocco, 1997.

BLANCHOT, M. O livro por vir. Tradução de Leyla Perrone-Moisés. São Paulo: Martins Fontes, 2005.

RAMOS, R. Circuito fechado. São Paulo: Globo, 2012.

SCHNEIDER, H. Contramão. Rio de Janeiro: Bertrand Brasil, 2007. 